\title{
INFLUENCE OF USING ADDITIVES ON QUALITY OF PELLETIZED FODDER
}

\author{
Iuliana Gageanu $^{1}$, Catalin Persu ${ }^{1}$, Dan Cujbescu ${ }^{1}$, Gabriel Gheorghe $^{1}$, Gheorghe Voicu ${ }^{2}$ \\ ${ }^{1}$ National Institute of Research-Development for Machines and Installations Designed to Agriculture \\ and Food Industry, Romania; ${ }^{2}$ University Politehnica of Bucharest, Romania \\ iulia.gageanu@gmail.com, persucatalin@yahoo.com,dcujbescu@yahoo.com, \\ gabrielvalentinghe@yahoo.com, ghvoicu_2005@yahoo.com
}

\begin{abstract}
The animal husbandry sector has had a great increase in the last decades, mostly due to extensive population growth. One of the sectors that has registered an extensive growth is the zootechnical sector, which had to meet the constantly growing food requirements from human populations. Green fodder is one of the main and most healthy animal feeds, but has the disadvantage that it is not available all year long and it has to be preserved. In order to be able to ensure healthy and nourishing animal feed throughout the entire year it is necessary to find ways to preserve green fodder in order to maintain its quality and nutritional properties. One of the ways to preserve green fodders' properties is to process them and turn them into pellets. This operation helps maintain homogeneity and store fodder in better conditions. The fodder pelleting process is largely influenced by the physico-chemical properties of the feed and the binders or additives used. The paper presents the experimental researches conducted for pelleting green fodder (alfalfa, wheat and rapeseed stalks) aimed to be used as animal feed and bedding, with and without using additives (corn starch and sugar beet). Following the experiments, series of analyses were performed to assess their quality. The use of additives was found to have a beneficial effect on the main quality attributes of animal feed pellets: better aspect, length, improved nutritional quality (from 3965.56 to 3989.08 by adding sugar beet), improved durability (from 87.2 to $94.5 \%$ by adding corn starch), etc. This study has demonstrated the existence of direct proportionality (influence) between the pelleting process, main raw materials and the additives used and the quality parameters of animal feed pellets.
\end{abstract}

Keywords: fodder, pellets, additives, nutritional quality.

\section{Introduction}

Extensive population growth has led to increased development of the zootechnical sector. One of the problems of this sector is seasonality of animal feed. Therefore, solutions were provided for ensuring good quality feed throughout the year. One of these solutions is to compact the animal feed, thus also providing the possibility to obtain recipes depending on the dietary of each animal.

Pellets are considered to be the optimum treatment in the case of compacted animal feed. Pelleting represents the process of compacting materials that were previously grinded to the desired sizes, by introducing them into special equipment and forcing them to pass through the cylindrical orifices of a plane or ring die. Pelleting biomass the bulk density increases from $\leq 100 \mathrm{~kg} \cdot \mathrm{m}^{-3}$ $\mathrm{la} \approx 600 \mathrm{~kg} \cdot \mathrm{m}^{-3}[1-4]$.

Also, fodder compaction is beneficial because: the air between particles is eliminated and a protective outer surface is created, thus significantly reducing the problems caused by vitamin degrading due to oxygen, moisture, heat, light and fats becoming rancid [5;6].

The fodder pelleting process is largely influenced by the physico-chemical properties of the feed and the binders or additives used. Fodder granulation also has a special influence. Generally, the finer the granulation of the fodder components, the easier the pelleting will be and the particles will be more strongly intertwined. However, a too fine grain size of the fodder prevents compaction. The components of the feed mixture also influence the pelleting process through their specific properties.

According to numerous research studies, such as [7-11], the use of binders, additives or introduction of another type of biomass materials can cause an increase in the kinetic durability of the pellets obtained, reduction of power consumption during the pelleting process and series of changes in the energy value, ash content of pellets, etc.

The paper follows series of experiments and analyses conducted for obtaining animal feed in the form of pellets, for improving their quality and optimizing the production process.

\section{Materials and methods}

In order to conduct the study in the process of pelleting animal feed, a ring die pelleting machine was used. The pelleting machine has the productivity of $120 \mathrm{~kg} / \mathrm{h}$. In this equipment, the biomass material is introduced inside the feeding bunker, from where it will fall inside the press, where it is 
forced to pass through the cylindrical orifices of the die. Pellets are afterwards cut by a blade and evacuated through an outlet. All biomass material was grinded to the same size $(<5 \mathrm{~mm})$ and was dried to the same moisture value (13\%).

For the experiments of pelleting fodder we used series of raw materials in the form of agricultural biomass suitable to be used as animal feed, in combination with additives used for improving the quality of the products obtained. These materials and the proportions used are shown in Table 1.

Table 1

Recipes used for pelleting animal feed

\begin{tabular}{|c|l|c|}
\hline $\begin{array}{c}\text { Sample } \\
\text { No. }\end{array}$ & \multicolumn{1}{|c|}{ Biomass material } & Additives used \\
\hline 1 & Alfalfa 100\% & - \\
\hline 2 & Wheat straws 100\% & - \\
\hline 3 & Rapeseed stalks 100\% & - \\
\hline 4 & Wheat straws 50 \% + Rapeseed stalks 50\% & - \\
\hline 5 & Wheat straws 95\% & Corn starch 5\% \\
\hline 6 & Alfalfa 95\% & Corn starch 5\% \\
\hline 7 & Alfalfa 95\% & Sugar beet 5\% \\
\hline
\end{tabular}

After obtaining the 7 types of animal feed pellets (Fig. 1), they were submitted to series of tests (analyses) of the components for determining important quality parameters and to assess the improvements brought by mixing the raw materials and by adding corn starch and sugar beet.

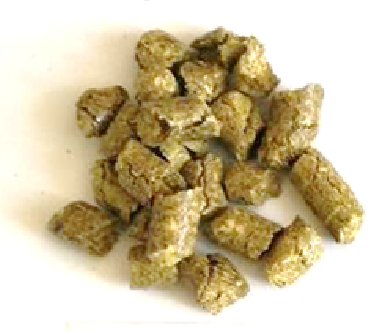

a)

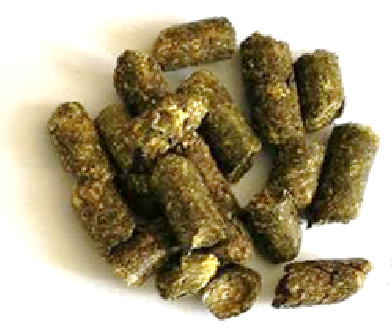

b)

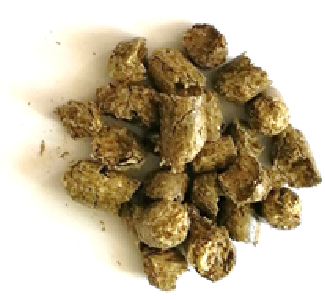

c)

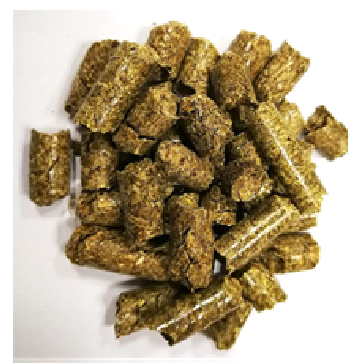

d)

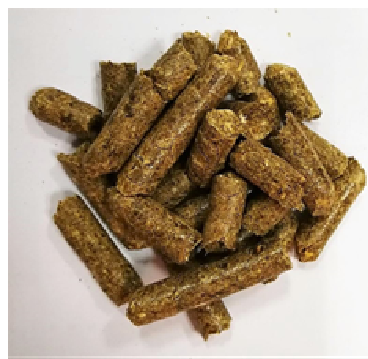

e)

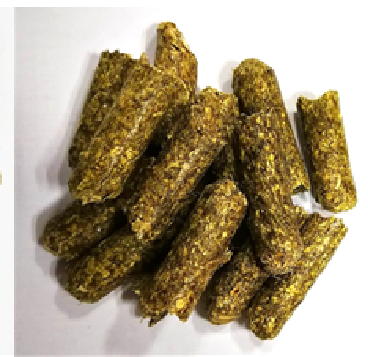

f)

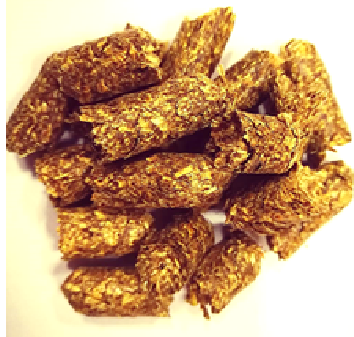

g)

Fig. 1. Samples of pellets obtained during experiments: a - wheat straws $100 \%$; b - alfalfa $100 \%$; $\mathrm{c}$ - rapeseed $100 \% ; \mathrm{d}$ - wheat straws $50 \%$ + rapeseed stalks $50 \%$; e - wheat straws $95 \%+$ corn starch $5 \% ; \mathrm{f}$ - alfalfa $95 \%$ + corn starch $5 \% ; \mathrm{g}$ - alfalfa $95 \%$ + sugar beet $5 \%$

The first thing analysed was the overall aspect of pellets (pellets were visually analysed to determine the state of their surface, formation of dust, occurrence of cracks or pellet loosening after exiting the die orifice).

Other analyses in the pellets obtained were conducted using the equipment presented in Table 2.

All samples for analysis were prepared according to the specifications in the standard ISO 14780:2016 standard - Solid biofuels: Sample preparation [12]. 
Equipment used for conducting the experiments

\begin{tabular}{|l|c|}
\hline \multicolumn{1}{|c|}{ Equipment / type } & $\begin{array}{c}\text { Measure domain / } \\
\text { division }\end{array}$ \\
\hline $\begin{array}{l}\text { Precision weighing scales /AW 220 M, with self-calibration } \\
\text { (Shimadzu - Japan) }\end{array}$ & $0 \div 200 \mathrm{~g} / 0.1 \mathrm{mg}$ \\
\hline $\begin{array}{l}\text { Furnace with temperature adjustment / UFE 500 (Memmert - } \\
\text { Germany) }\end{array}$ & $0 \div 260{ }^{\circ} \mathrm{C} / 1^{\circ} \mathrm{C}$ \\
\hline Calorimeter /CAL 2k (DDS Calorimeters - South Africa) & $0.001 \mathrm{MJ} \mathrm{kg-1}$ \\
\hline Calcination oven, with P 320 controller (Naberterm - Germany) & $0 \div 1400^{\circ} \mathrm{C} / 10^{\circ} \mathrm{C}$ \\
\hline Olympus Inverted Microscope CKX53 & - \\
\hline Perkin Elmer model PinAAcle 900T & - \\
\hline
\end{tabular}

\section{Methods of analysis used:}

\section{Moisture content}

The moisture content Mc (\%) was determined on a wet basis, according to the method described in the standard ISO 18134-1:2015 standard - Solid biofuels - Determination of moisture content Oven dry method - Part 1: Total moisture - Reference method [13].

\section{Energy content}

The energy content of the pellet samples was determined using the calorimeter bomb, according to the specification found in the ISO 18125:2016 standard - Solid biofuels - Determination of calorific power [14].

3. Phosphorus (P), Natrium (Na), Potassium (K), Iron (Fe), Magnesium (Mg) and Calcium (Ca) content

Phosphorus $(\mathrm{P})$, natrium $(\mathrm{Na})$, potassium $(\mathrm{K})$ and calcium $(\mathrm{Ca})$ content $(\%)$ was determined according to the method described in the standard SR EN ISO 16967:2015 - Solid biofuels. Determination of major elements - Al, Ca, Fe, Mg, P, K, Si, Na and Ti [15].

Principle:

The samples were digested in a closed vessel using reagents, temperature and pressure. The digestion was carried out directly on the pellet samples. Detection of the elements was done by inductively coupled plasma optical emission spectrometry (ICP-OES).

Reagents:

- deionised water - containing negligible amounts of major elements (which do not contribute significantly to the analysis) [16];

- $\quad$ nitric acid (HNO3), $\geq 65 \%(\mathrm{w} / \mathrm{w}), \rho=1.41 \mathrm{~g} \cdot \mathrm{ml}^{-1}$;

- hydrogen peroxide (H2O2), $30 \%(\mathrm{w} / \mathrm{w}), \rho=1.11 \mathrm{~g} \cdot \mathrm{ml}^{-1}$;

- hydrofluoric acid (HF), $40 \%(\mathrm{w} / \mathrm{w}), \rho=1.11 \mathrm{~g} \cdot \mathrm{ml}^{-1}$;

- $\quad$ boric acid (H3BO3), $4 \%(\mathrm{w} / \mathrm{w})$.

Working technique:

$500 \mathrm{mg}$ of a ground and homogenized sample were mixed with $3.0 \mathrm{ml} \mathrm{H} 2 \mathrm{O} 2,8.0 \mathrm{ml} \mathrm{HNO} 3$ and $1.0 \mathrm{ml} \mathrm{HF}$ in a closed digestion vessel. The reaction time of $5 \mathrm{~min}$ was kept before closing the vessel. The sample was heated according to the provision in the standard and afterwards was cooled to room temperature. HF was neutralized by adding $10 \mathrm{ml} \mathrm{H3BO3.} \mathrm{The} \mathrm{sample} \mathrm{was} \mathrm{reheated,} \mathrm{cooled} \mathrm{down} \mathrm{and}$ transferred to a volumetric flask and deionised water was added to the appropriate level. The test portions obtained were analysed.

A blank test portion was prepared, using the same method as described above, but without the test portion.

For detection of $\mathrm{P}, \mathrm{NA}, \mathrm{K}, \mathrm{Fe}, \mathrm{Mg}$ and $\mathrm{CA}$ in the samples we used the ICP-OES method according to the standard SR EN ISO 11885:2009. 
The content of each element in the samples for testing on dry basis $\left(\mathrm{w}_{\mathrm{i}}\right)$ was calculated using the following formula:

$$
w_{i}=\frac{\left(c_{i}-c_{0}\right) \times V}{m} \times \frac{100}{\left(100-M_{a s}\right)}
$$

where $w_{i}$ - concentration of the element in the test sample, $\mathrm{mg} \cdot \mathrm{kg}^{-1}$;

$c_{i}-$ concentration of the element in the diluted test portion, $\mathrm{mg} \cdot \mathrm{l}^{-1}$;

$c_{0}$ - concentration of the element in the blank test portion, $\mathrm{mg} \cdot \mathrm{l}^{-1}$;

$V$ - volume of the diluted test portion, $\mathrm{ml}$;

$m$ - mass of the pellet sample for analysis used, g;

$M_{a s}$ - moisture content in the pellet sample for analysis, $\%$.

\section{Lipid content}

The fat content of pellet samples was determined through the Soxhlet method, based on repeated extraction of lipids from the samples using petroleum ether, followed by solvent removal and weighing the fatty residue obtained.

\section{Mechanical durability of pellets}

The durability of pellets during handling, transport and storage was determined using a special pellet tester, according to the specifications given in the standard SR EN ISO 17831-1:2016 - Solid biofuels - Determination of mechanical durability of pellets and briquettes - Part 1: Pellets [17].

\section{Specific energy consumption per kilogram of pelletized fodder}

The specific energy consumption for each sample was determined using a digital multimeter during the process of pelleting.

\section{Results and discussion}

Based on the methods previously mentioned, after the analysis conducted, the following results were obtained (Table 3 and figure):

Results obtained from the analysis of pellets

Table 3

\begin{tabular}{|c|c|c|c|c|c|c|c|c|c|c|c|}
\hline \multirow{2}{*}{$\begin{array}{c}\text { Sample } \\
\text { no. }\end{array}$} & $\begin{array}{c}\text { Moisture, } \\
\%\end{array}$ & $\begin{array}{c}\text { Energy, } \\
\mathrm{kcal} \cdot \mathrm{kg}^{-1}\end{array}$ & $\mathrm{P}, \%$ & $\mathrm{Na}, \%$ & $\mathrm{~K}, \%$ & $\mathrm{Fe}, \%$ & $\mathrm{Mg}, \%$ & $\mathrm{Ca}, \%$ & $\begin{array}{c}\text { Lipids } \\
\%\end{array}$ & $\begin{array}{c}\text { Mechanical } \\
\text { durability, \% \% }\end{array}$ & $\begin{array}{c}\text { Energy } \\
\text { consumed, } \\
\text { kJ per kg of } \\
\text { pellets }\end{array}$ \\
\hline 1 & 9.72 & 3817.12 & 0.294 & 0.380 & 2.976 & 0.084 & 0.028 & 0.833 & 1.091 & 87.2 & 595 \\
\hline 2 & 8.16 & 3965.56 & 0.080 & 0.025 & 1.108 & 0.025 & 0.019 & 0.119 & 1.072 & 89.4 & 596 \\
\hline 3 & 10.54 & 3780.21 & 0.171 & 0.051 & 1.846 & 0.018 & 0.021 & 0.112 & 1.068 & 87.5 & 594 \\
\hline 4 & 8.67 & 3859.75 & 0.138 & 0.035 & 1.411 & 0.023 & 0.021 & 0.121 & 1.071 & 88.3 & 594 \\
\hline 5 & 7.68 & 3885.78 & 0.113 & 0.057 & 1.106 & 0.022 & 0.018 & 0.102 & 1.073 & 94.5 & 605 \\
\hline 6 & 8.3 & 3921.85 & 0.784 & 0.364 & 2.741 & 0.070 & 0.025 & 0.784 & 1.090 & 92.7 & 601 \\
\hline 7 & 11.93 & 3989.08 & 0.928 & 0.478 & 2.912 & 0.208 & 0.037 & 0.28 & 1.195 & 84.9 & 592 \\
\hline
\end{tabular}

It can be observed that the moisture content of the pellets registered the values ranging between $8.16 \%$ and $8.3 \%$ for the pellets obtained without using additives and between $7.68 \%$ and $11.93 \%$ for the pellets obtained using additives, indicating that additives are beneficial for decreasing moisture and keeping it under $10 \%$, the desired value for optimal storage and use. The exception comes from alfalfa pellets combined with sugar beet, which have moisture of $11.93 \%$, due to the fact that sugar beet has high water content.

The energy values registered increased for all samples using additives, especially for alfalfa samples combined with sugar beets, which registered the highest increase compared to alfalfa pellets, from 3885.78 to $3989.08 \mathrm{kcal} \cdot \mathrm{kg}^{-1}$.

Opposite to the results obtained in paper [2], the use of starch caused the specific energy consumption to have a small increase, from 596 to $605 \mathrm{~kJ} \cdot \mathrm{kg}^{-1}$ for the pellets in the case of wheat samples, and from 596 to $601 \mathrm{~kJ} \cdot \mathrm{kg}^{-1}$ for the pellets in the case of alfalfa, explained by the fact that the 
starch absorbed the moisture in the material and it was harder for it to pass thorough the orifices, therefore requiring more energy.

In the case of using sugar beet the opposite occurred, the material passed more easily through the orifices, therefore we registered a small decrease from 595 to $592 \mathrm{~kJ} \cdot \mathrm{kg}^{-1}$.

As in paper [2], the use of corn starch determined an increase in durability for both samples with more than $5 \%$. Sugar beet addition caused a decrease in durability (less than $2.5 \%$ ).

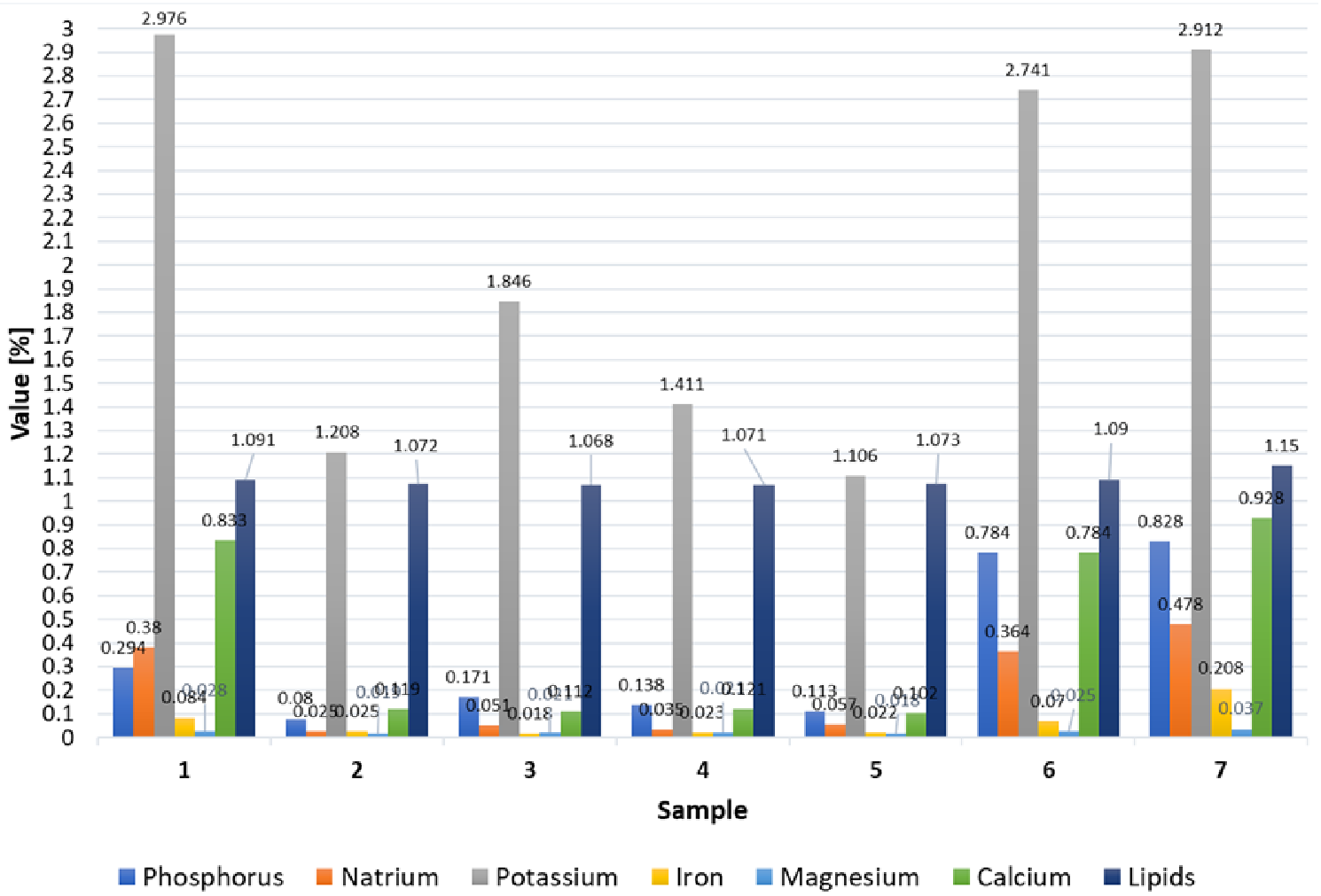

Fig. 2. Element content in samples analyzed

The analysis conducted for determining the component elements of the pellets obtained showed the benefits of adding corn starch and sugar beet to the composition of wheat and alfalfa pellets, increasing the content of calcium, phosphorus, potassium, natrium, iron and magnesium, indicating a high nutrient intake.

\section{Conclusions}

The visual analysis of the pellets has shown that by using additives in pelletizing recipes, products are obtained in a more regular form, with much less surface cracks, are better bound and shinier, indicating better storage attributes and manipulated. The exception is given by alfalfa + sugar beet pellets, which showed inferior surface qualities compared to alfalfa pellets and alfalfa + starch pellets.

The experimental researches showed that the use of additives had an overall beneficial effect on animal feed pellet recipes, mainly on their stability, storage characteristics and energy content, but also it gives a solution for ensuring quality animal feed made from green fodder throughout the entire year, thus overcoming the shortage of quality fodder in winter and spring periods. Therefore, this study has demonstrated the existence of direct proportionality (influence) between the pelleting process, main raw materials and the additives used, and the quality parameters of animal feed pellets.

\section{Acknowledgements}

This work was supported by the Romanian Research and Innovation Ministry, through NUCLEU Programme, Project "Researches on the intensive polyculture growth of fish and the complex valorisation of aquatic bioresources (plants)", code PN 191002 03, contract no. 5N/07.02.2019 and through a grant on Programme 1 - Development of the national research-development system, 
subprogramme 1.2 - Institutional performance - Projects for financing excellence in RDI, contract No. 16PFE.

\section{References}

[1] Vukmirović D., Čolović R., Rakita S., Brlek T., Đuragić O., Solà-Oriol D. Importance of feed structure (particle size) and feed form (mash vs. pellets) in pig nutrition - A review, Animal Feed Science and Technology, 233, 2017. pp. 133-144.

[2] Stahl M., Berghel J., Frodeson S., Granstrom K., Renstrom R. Effects on Pellet properties and energy use when starch is added in the wood-fuel pelletizing process, Energy Fuels Journal, 26 (3). 2012. pp. 1937-1945.

[3] Wu M.R., Schott D.L., Lodewijks G. Physical properties of solid biomass, Biomass and bioenergy 35, 2011. pp. 2093-2105.

[4] Tabil L., Adapa P., Kashaninejad M. In biomass feedstock pre-processing: densification, Biofuel's Engineering Process Technology, M. A. Dos Santos Bernardes, Ed., 2011. pp. 439-464, InTech, NY, USA.

[5] Chelemen I. Zootechnical machines and installations - Part II, Ed. Polytechnic Institute Bucharest, Faculty of Agricultural Machinery, 1983.

[6] Florean R., Bică C. M., Şerban E. Unit operations - Mixing and agglomeration, Transylvania University Pub. House, Braşov, 2008.

[7] Sepelev I., Galoburda R. Industrial potato peel waste application in food production: a Review, Research for Rural Development, 1, 2013, pp. 130-136.

[8] Abedi A., Dalai A. K. Study on the quality of oat hull fuel pellets using bio-additives, Biomass and Bioenergy 106, 2017. pp. 166-175.

[9] Kuoyao L., Jingyi C., Zhujun S., Gang T., Dong Y., Delin C. Effects of raw material extrusion and steam conditioning on feed pellet quality and nutrient digestibility of growing meat rabbits, Animal nutrition, 3 (2), 2017, pp. 151-155.

[10] Obidzinski S., Piekut J., Dec D. The influence of potato pulp content on the properties of pellets from buckwheat hulls, Renewable Energy 87, 2016. pp. 289-297.

[11] Kirstena C., Lenza V., Schröder H.W., Repke J.U. Hay pellets - The influence of particle size reduction on their physical - mechanical quality and energy demand during production, Fuel Processing Technology 148, 2016. pp. 163-174.

[12] ISO 14780:2016 standard- Solid Biofuels. Sample preparation.

[13] ISO 18134-1:2016 standard- Solid biofuels - Determination of moisture content - Oven dry method - Part 1: Total moisture - Reference method.

[14] ISO 18125:2016 standard - Solid biofuels - Determination of calorific power.

[15] ISO 16967:2016 standard - Solid biofuels - Determination of major elements - Al, Ca, Fe, Mg, P, $\mathrm{K}, \mathrm{Si}, \mathrm{Na}$ and $\mathrm{Ti}$.

[16] ISO 11885: 2007 standard- Water quality - Determination of selected elements by inductively coupled plasma optical emission spectrometry (ICP-OES).

[17] SR EN ISO 17831-1:2016 - Solid biofuels - Determination of mechanical durability of pellets and briquettes - Part 1: Pellets 